\title{
Behaviour disturbances during recovery from herpes simplex encephalitis
}

\author{
RICHARD GREENWOOD, ${ }^{*}$ ASHOK BHALLA, ${ }^{*}$ ALAN GORDON, $\dagger$ JEREMY ROBERTS* \\ From The National Hospitals for Nervous Diseases, London, ${ }^{*}$ and the Department of Neurophysiology, \\ Southend Hospital, $\uparrow$ Southend, UK
}

SUMMARY Bizarre behaviour disturbances in four patients occurring during incomplete recovery from herpes simplex encephalitis are described. Some aspects of their behaviour were similar to that originally described by Klüver and Bucy in monkeys following bilateral temporal lobectomy. Previous reports of behavioural disturbances in man after herpes simplex encephalitis are reviewed and attention drawn to the aggressive and disruptive behaviour that is often seen. With the reduced mortality in herpes simplex encephalitis in recent years it is possible that behaviour disturbances such as those described here will be seen more frequently.

Herpes simplex virus, type 1 , is probably the commonest cause of acute sporadic necrotising encephalitis in temperate climates. Its clinical and pathological features are now well recognised ${ }^{1}$ as is the tendency for the necrotic lesions to localise in the inferior and medial parts of the temporal lobes and the orbito-frontal cortex. Recently this has been demonstrated during life by CT scanning. ${ }^{2}$ This localisation may be related to the route of entry of the virus into the brain, either via the olfactory tracts $^{3}$ or via fibres from the trigeminal ganglion supplying the basal meninges of the middle and anterior fossae ${ }^{4}$ and results in the characteristic focal neurological features seen at presentation. Olfactory, gustatory and auditory hallucinations, speech and memory disturbances, and bizarre behaviour abnormalities leading to psychiatric consultation are all well documented.

Documented neurological deficits in survivors also accord with known limbic and temporal lobe mechanisms. A residual amnesic syndrome, originally described by Rose and Symonds, ${ }^{5}$ and subsequently reported by others, ${ }^{16-8}$ is now well recognised. Behavioural disorders following herpes simplex encephalitis are less well documented. Oxbury and Maccallum ${ }^{9}$ give some details of ten survivors, two of whom exhibited behaviour disturbances reminiscent of the Klüver-Bucy syndrome. A much more detailed account of the cognitive, behavioural

Address for reprint requests: Dr R Greenwood, Hurstwood Park Neurological Centre, Haywards Heath, W. Sussex, RH17 7SJ, UK.

Received 17 March 1983

Accepted 16 April 1983 and emotional deficits in ten survivors of a necrotising limbic encephalitis, probably due to herpes simplex, is given by Hierons, Janota and Corsellis. ${ }^{10}$ Klüver-Bucy features were seen in some patients and this, they point out, emphasises the focal nature of the encephalitis, as does the amnesic deficit. Other authors have described single cases in the same light ${ }^{1112}$ or as examples of the Klüver-Bucy syndrome in man. ${ }^{13-18}$

Although mortality in herpes simplex encephalitis has probably been reduced in recent years, ${ }^{19}$ the incidence of deficit in survivors is still high; such deficits will thus be seen more frequently in the future. This aspect of the illness has received little attention in the past, apart from the literature cited above. In their monograph on herpes simplex encephalitis Illis and Gostling, ${ }^{1}$ for instance, devote only two paragraphs to the neurological sequelae. Behaviour disturbances following herpes simplex encephalitis are probably more common than is generally recognised. We have recently observed bizarre behaviour disturbances in four patients during incomplete recovery from herpes simplex encephalitis and report them here.

\section{Case reports}

Case 1 On 18 January 1980 JBR, a 23-year-old international sportsman and electronics undergraduate, complained of a "funny smell". The following day he became pyrexial and developed a sore throat and headache. On 22 January 1980 , following a grand mal seizure, he was admitted to the local hospital. He was alert and febrile and his neck was stiff. CSF examination revealed a protein of 0.56 
$\mathrm{g} / \mathrm{l}$, a sugar of $4.2 \mathrm{mmol} / \mathrm{l}$ and 46 white cells $/ \mathrm{mm}^{3}, 90 \%$ of which were lymphocytes. Over the next forty-eight hours he became drowsy, his pupils became unequal, and he was transferred to the National Hospitals for Nervous Diseases. On examination, he was pyrexial, his chest was clear and he had no rash or hepatosplenomegaly. He was awake but disorientated in place and time and obeyed commands erratically. His speech was fluent but inappropriate. His mental state was interrupted by periods of vacancy and immobility. His neck was stiff and Kernig's sign was positive. Fundoscopy showed early disc swelling; eye movements were full, reflexes were symmetrical and plantars were flexor. Sensation was intact.

Investigations showed normal $\mathrm{Hb}, \mathrm{WBC}$, differential white count, ESR, liver function tests and auto-antibodies. Paul-Bunnell and screen for hepatitis B antigen were negative. CT head scan showed widespread low attenuation in both hemispheres compatible with encephalitis. EEG showed repetitive complexes bilaterally, maximal in the left temporal region, and slow background activity. Focal epileptic activity coinciding with the periods of immobility was also seen over the left temporal region. Further CSF examination on 24 January 1980 showed a protein of 1.30 $\mathrm{g} / \mathrm{l}$, a sugar of $2.2 \mathrm{mmol} / \mathrm{l}, 272$ mononuclear cells and 20 red cells $/ \mathrm{mm}^{3}$ and a mid-zone Lange curve. No organisms were seen, syphilis serology was negative, and cultures for fungi and mycobacteria were negative. IgG was $16.5 \%$ of the total protein and electrophoresis showed changes consistent with a traumatic tap.

A clinical diagnosis of herpes simplex encephalitis was made. Treatment with dexamethasone and phenytoin and a ten-day course of adenine arabinoside was begun. His conscious level initially deteriorated, but after six days he became more alert and his fever settled. His fits were controlled with oral phenytoin alone. Virological studies were repeated on 5 February 1980 and showed a rise in serum and CSF titres to herpes simplex virus without a rise in titres to measles, and a low ratio of titres in blood and CSF to herpes simplex compared with the corresponding ratio to measles (table).

Although he became more active and alert he remained very confused. Toward the end of the third week of the illness various bizarre behaviour problems became apparent. The most obvious of these was his tendency to eat or drink everything within reach. He drank shampoo, his own urine and water from flower vases and persistently tried to

Table

\begin{tabular}{|c|c|c|c|c|}
\hline \multirow{2}{*}{ Days after onset } & \multicolumn{2}{|l|}{$3-7$} & \multicolumn{2}{|l|}{$10-24$} \\
\hline & Serum & $C S F$ & Serum & $C S F$ \\
\hline $\begin{array}{l}\text { JBR } \\
\text { Herpes simplex } \\
\text { Measles }\end{array}$ & $\begin{array}{l}16 \\
64\end{array}$ & $\begin{array}{l}<4 \\
<4\end{array}$ & $\begin{array}{r}512 \\
64\end{array}$ & $\begin{array}{r}32 \\
<4\end{array}$ \\
\hline $\begin{array}{l}\text { TM } \\
\text { Herpes simplex } \\
\text { Rubella }\end{array}$ & $\begin{array}{r}64 \\
1024\end{array}$ & $\begin{array}{r}4 \\
<4\end{array}$ & $\begin{array}{r}256 \\
1024\end{array}$ & $\begin{array}{r}32 \\
<4\end{array}$ \\
\hline $\begin{array}{l}\text { KB } \\
\text { Herpes simplex } \\
\text { Measles } \\
\text { EH }\end{array}$ & $\begin{array}{l}80 \\
40\end{array}$ & $=$ & $\begin{array}{r}320 \\
40\end{array}$ & $\bar{z}$ \\
\hline $\begin{array}{l}\text { Herpes simplex } \\
\text { Rubella }\end{array}$ & 二 & 二 & $\begin{array}{l}20 \\
20\end{array}$ & $\begin{array}{r}2 \\
<2\end{array}$ \\
\hline
\end{tabular}

Titres are expressed as reciprocals of serum dilution. obtain water from taps in the ward. He would sit impassively in the ward, repeatedly asking for "a drink" but did not show aggressive behaviour if it was refused. His 24hour urine output varied between 5 and 7 litres, and a water deprivation test demonstrated urine concentrations up to $650 \mathrm{mmol} / \mathrm{kg}$ whilst the plasma osmolality was maintained at $275 \mathrm{mmol} / \mathrm{kg}$. He tended to place all solid objects in reach in his mouth and chew them, including soap, his own faeces, his urinary catheter, paper, blankets and sheets. This indiscriminate eating and drinking lasted seven to ten days. His facial expression during this period and afterwards was rather impassive and to many observers he looked slightly aggressive. However, he never showed any aggressive behaviour towards staff or relatives. Bizarre sexual behaviour was not seen. Gradual recovery continued and on 21 April 1980 he obtained a verbal IQ of 98 and a performance IQ of 85 . However, he was disabled by a very severe amnesic syndrome and was unable to remember events for more than thirty seconds; memory for events long before his illness was also severely impaired. He had severe visual and verbal recognition difficulties with particular difficulty in identifying names and pictures of foods, plants and animals but performed relatively well with inanimate objects. These categoryspecific agnosic defects are reported in greater detail by Warrington. ${ }^{20}$

Some recovery continued over the next year. Repeat CT scan in August 1980 showed patchy bitemporal areas of low attenuation (fig A). An EEG was normal. He remained incapacitated by his memory disturbance. Currently he lives at home and requires constant supervision. He can wash, dress and feed himself and is helped throughout the day by lists of instructions for different tasks. He recognises close relatives but not other faces seen earlier during the day. $\mathrm{He}$ is able to go out cycling, using relevant signals on the road, but gets lost easily; when lost he is able to ask the way and follow clear instructions. He is able to do rote clerical tasks under close supervision and performs simple tasks on a calculator. Attempts at rehabilitating him further have been frustrated by uncontrollable outbursts of rage and aggression which seem to be triggered when he feels ignored and frustrated. These also occur at home under similar circumstances.

Case 2 TM, a 15-year-old schoolboy, was well until 21 September 1980 when he developed rhinorrhoea, sore throat and cough. He continued at school until 27 September 1980 when he complained of headache, anorexia and photophobia, and vomited. He was apparently better on 29 September 1980 but the following morning was confused and deluded, complaining of "a black cat upstairs". He was pyrexial, complained of headache, and that evening had a grand mal fit. He remained unconscious following the fit, was admitted to hospital and the following day transferred to St Bartholomew's Hospital, still unconscious. On admission he did not respond to commands but did, purposefully, to pain. He was pyrexial, his neck was stiff and there was a herpetic sore on his lower lip. He tended to bite objects placed between his teeth. There were no focal signs in the limbs save an extensor left plantar response. CSF showed a protein of $0.79 \mathrm{~g} / \mathrm{l}$, sugar $5.4 \mathrm{mmol} / \mathrm{l}, 293 \mathrm{red}$ cells and 115 white cells $/ \mathrm{mm}^{3} ; 75 \%$ of the latter were lymphocytes. Urea and electrolytes, blood 

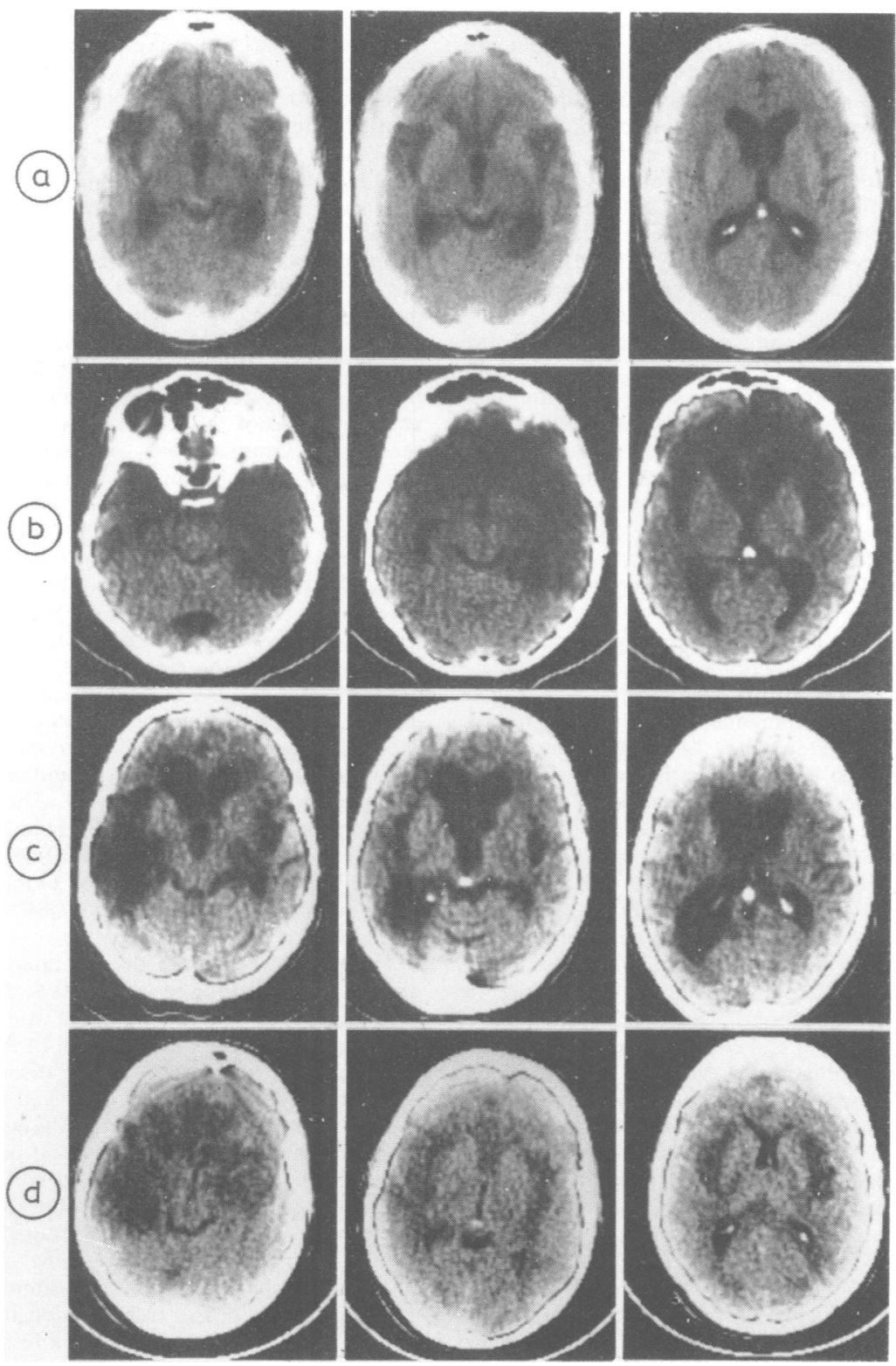

Fig CT scans without contrast in JBR (A) at 8 months, TM (B) at 3 months, KB (C) at 2 years and $E H(D)$ at 2 weeks, showing bilateral temporal $(J B R, K B)$ and fronto-temporal (TM,EH) low attenuation, most extensive on the left in JBR, KB and $E H$, and on the right in TM. Ventricular enlargement is seen in TM and $K B$, whilst small ventricles, implicating persistent oedema, are seen in the early scan in $E H$. Despite relatively minor pathology visible in JBR his functional deficit remains severe. 
count, ESR and liver function tests were normal. CT scan showed patchy low attenuation in both hemispheres and compression of the right lateral ventricle. EEG showed repetitive complexes which were widespread over both hemispheres. A clinical diagnosis of herpes simplex encephalitis was made and dexamethasone, phenytoin and a ten day course of acycloguanosine were started. Over the next week his condition slowly deteriorated; he developed papilloedema and decerebrate posturing on the left and then bilaterally and the right pupil dilated. $A$ repeat $C T$ scan showed well defined low attenuation in the right temporal and both frontal regions with shift to the left. A right temporal decompression was thus performed on 10 October 1980. Following this his cerebral status began to improve but he developed staphylococcal pneumonia, pneumothorax and lung abscess. These were successfully treated with antibiotics, drainage and tracheostomy, the latter being performed on 21 October 1980. A right temporal biopsy was obtained at decompression but was thought to be too small and superficial to yield useful material; no inclusion bodies were found on light or electron microscopy. Virological studies on serum and CSF showed a rise in titre to herpes simplex in serum and CSF between 2 October 1980 and 20 October 1980 without a rise in titre to rubella, and a low ratio of titres in blood and CSF to herpes simplex compared with the corresponding ratio of rubella titres (table).

After four weeks of intensive care he was transferred back to the general ward with a spastic quadriparesis, worse on the left. He was awake and alert but was unable to respond rationally to commands and was tooth grinding. At the beginning of December he became more cooperative and was able to play a simple game of noughts and crosses. He would carry out commands but would not respond verbally beyond one or two words of reply to questions. In mid December he became more active but less co-operative. He would shout and swear and throw objects around. He would sit spitting every minute or so for long periods to no obvious purpose and would redirect his spittle if asked to do so; he would not stop spitting, however, saying that he "could not help it". He would bite at objects placed near his mouth, eat and throw his faeces and food around the room and chew paper, his bed covers and other inedible objects. In view of this apparent deterioration in his behaviour and the evidence of mild to moderate ventricular dilatation in the absence of sulcal prominence on CT scan (fig B) a ventriculo-atrial shunt was performed on 21 January 1981 . This did not result in any immediate obvious improvement.

By May 1981 he had stopped attempting to eat or throw his faeces. He was, however, doubly incontinent and frequently tried to open his urine bag and drink his urine. He ate food voraciously and would spit it out and eat it again repeatedly. He still chewed paper and his bed covers and would summon attention by shouting obscenities or throwing things around. By contrast he could play a very simple game of chess though with minimal change of strategy when required. He would co-operate during simple conversation though without apparent interest. He knew the name of the prime minister, the hospital he was in and the names of various current footballers. Deviant sexual behaviour was not observed. Psychological testing was difficult but he was taken through the verbal scale of the WAIS, scoring the equivalent of IQ 117 on similarities, 99 on mental arithmetic, 88 on digit span and vocabulary and in the mildy mentally retarded range on general knowledge and comprehension. Block design was performed correctly with four blocks but using nine his performance became disorganised and he would swear loudly. It was felt that while memory was reasonably intact, reasoning and conceptual abilities were poor.

Case $3 \mathrm{~KB}$, a 58-year-old housewife, was admitted to Rochford Hospital on 22 June 1979 having developed frontal headache, fever and increasing confusion over the preceding 48 hours. On admission she was pyrexial, drowsy and disorientated in time and place. A nominal dysphasia was noted but there were no other focal neurological signs. Lumbar puncture produced cerebrospinal fluid at normal pressure with a predominantly lymphocytic pleocytosis (39 WBC/mm 3 , 60\% lymphocytes) and a glucose of $2.7 \mathrm{mmol} / 1$. No micro-organisms were seen with Gram's stain and subsequent cultures for pyogens and mycobacteria were negative. Following transfer to Oldchurch Hospital she was treated with dexamethasone and a CT scan on 23 June 1979 disclosed low attenuation in the left temporal lobe; an EEG showed a diffuse abnormality with a focal slow-wave disturbance over the left temporal region. CSF on 27 June 1979 continued to show a lymphocytic pleocytosis $\left(120 \mathrm{WBC} / \mathrm{mm}^{3}\right.$, all lymphocytes), the glucose was $2.6 \mathrm{mmol} / \mathrm{l}$ and protein $1.17 \mathrm{~g} / \mathrm{l}$. Microscopy and culture were again negative. A clinical diagnosis of herpes simplex encephalitis was made. Steroids were continued for ten days and over this time her drowsiness and pyrexia resolved and on 13 July 1979 CSF contained only 10 lymphocytes. The antibody titre to herpes simplex virus in peripheral blood rose from 1 in 80 on 27 June 1979 to 1 in 320 on 6 July 1979 before falling again. No significant change of blood antibody titre to other common viruses occurred. CSF viral titres were not measured.

The patient remained disorientated in time and place and profoundly amnesic for events from minute to minute with a fluent dysphasia amounting at times to jargon. Following return to her local hospital (4 August 1979) it was observed that in addition to her disorientation, amnesia and jargon dysphasia, she displayed a tendency to put foreign objects into her mouth. She was noted at various times to chew flowers (roses), a salt pot, paper, soap and other inedible items from around her bed. This phase of unusual oral behaviour persisted for about one month. No uninhibited or aberrant sexual behaviour was witnessed during this period. By May 1981 she had recovered sufficiently to be able to complete simple household chores given to her. A severe memory deficit remained and she would forget eating a meal after a few minutes. The only person she appeared to recognise was her husband. She ate any food placed in front of her though was not hyperphagic, merely "inappropriately normophagic". ${ }^{42}$ She tended to become tearful and would repeat questions such as "I am worth it, aren't I?" repeatedly. She would greet other patients, doctors and nurses with a kiss. She had a fluent dysphasia with severe naming problems and considerable difficulties with comprehension, repetition, 
reading and recognition; her verbal IQ was 70 and performance IQ 76. CT scan (fig C) showed bitemporal low attenuation, left more than right, with ventricular dilatation.

Case $4 \mathrm{EH}$, a 29-year-old Irish labourer, was admitted to Guy's Hospital on 8 May 1980 with a three day history of increasing confusion and disorientation. He was known to be a heavy drinker but his past history was otherwise unremarkable. On admission he was pyrexial, confused and disorientated. A chest radiograph showed patchy right basal changes and he was started on antibiotics. The following day he had a grand mal fit preceded by turning of the head and eyes to the right. CT scan on 10 May 1980 showed patchy low attenuation in both hemispheres especially in the left fronto-temporal region. CSF showed a protein of $0.83 \mathrm{~g} / \mathrm{l}$, sugar $4.1 \mathrm{mmol} / \mathrm{l}, 36 \mathrm{red}$ cells and 24 white cells $/ \mathrm{mm}^{3}, 60 \%$ of the latter being lymphocytes. EEG showed bilateral generalised slow-wave activity. A clinical diagnosis of herpes simplex encephalitis was made and he was given a ten-day course of adenine arabinoside. Throughout this time he remained confused, uncooperative, dysphasic and drowsy. CSF and serum herpes simplex virus antibody titres on 15 May 1980 showed a high CSF to serum ratio without rise in titres to mumps, measles or adenovirus, and CT scan (fig D) showed persistence of the fronto-temporal low attenuation most marked on the left. After ten days he became more alert but remained confused and unco-operative. By 4 June 1980 he was mobile but disruptive, walking about the ward drinking liquids of all kinds, searching other patients property and climbing out of windows and down fire escapes. He appeared uninterested and flat during simple exchanges but if pressed was resistant and suspicious and tended to be aggressive verbally though not physically. He would pick up anything he came across and sometimes put it into his mouth. He could light a cigarette and use a knife and fork but was unable to recognise close relatives or understand simple commands. He could by contrast play a simple game of cards. He was doubly incontinent.

Over the next six months he became facile and cooperative, usually continent and able to carry out simple commands. He could count up to 20 , knew right from left and the days of the week but his memory remained extremely impaired and he did not know his date of birth or home address.

\section{Discussion}

All of these four patients were left severely disabled by their illness. Case 1 (JBR) remained severely amnesic, had verbal and visual identification difficulties and tended to fly into a rage. Case 2 (TM) was moderately demented and had a florid and rather aggressive behaviour disturbance. Case 3 (KB) was severely amnesic and dysphasic, rather facile and moderately demented and case 4 (EH) was initially aggressive, later facile and remained severely demented. All required some sort of long-term care.

All four cases had evidence of bilateral pathology: in cases 1,3 and 4 the left fronto-temporal regions were most involved whilst case 2 showed more severe changes on the right. Despite the lack of histological support for the diagnosis herpes simplex clearly appears to have caused the encephalitis in cases 1 and 2 and would seem to be the most likely cause in cases 3 and 4 . All cases presented as an encephalitic illness with focal features, pyrexia and typical CSF changes. Periodic complexes of the sort seen in herpes simplex encephalitis were seen in cases 1 and 2 . Virological studies strongly supported the diagnosis in cases 1 and 2 and were compatible with the diagnosis in cases 3 and 4, and CT scan in all four cases showed fronto-temporal low attenuation typical of herpes simplex encephalitis. ${ }^{2}$ These changes reflect the bitemporal necrosis involving the temporal neocortex and rhinencephalic structures that is commonly seen at post-mortem. ${ }^{10}$

Various deficits may follow bilateral medial temporal lobe and limbic destruction in man. An amnesic syndrome, initially described after herpes simplex encephalitis by Rose and Symonds, ${ }^{5}$ is now well recognised. Such patients have a severe and sometimes incapacitating disorder of memory and recall with relative preservation of other intellectual and neurological function. A similar deficit occurs after bilateral infero-medial temporal lobe resection $^{21}$ or infarction ${ }^{22-25}$ providing the lesions extend beyond the amygdala to include the hippocampi and hippocampal gyri. In general after surgical lesions the temporal neocortex remains intact and patients do not show marked changes in cognitive function, social behaviour, motivation or affect. ${ }^{26}$ Following infarction they may be mildly indifferent and lacking in initiative ${ }^{23}$ or agitated..$^{22}$

By contrast if both temporal neocortex and rhinencephalic structures are included in a bilateral surgical lesion then striking abnormalities of behaviour and affect occur in addition to the memory deficit. These changes were initially described in single cases following the introduction of bilateral temporal lobectomy for the treatment of behavioural and seizure disorders. ${ }^{27-29}$ Terzian and Dalle Ore $^{30}$ provide the fullest description in the literature of such a case. This patient had a severe memory deficit, was unable to recognise close relatives, repeatedly examined objects by hand without apparently recognising them, ate voraciously, displayed no emotion towards external stimuli of any sort and masturbated regularly. Although this patient repeatedly picked up and examined objects visually and had an insatiable appetite he did not place non-food objects in his mouth, chew them or attempt to eat them. Similar symptoms have been described by a number of authors early in the course of Pick's disease and during the terminal phases of Alzheimer's disease. ${ }^{31-34}$ 
The changes in behaviour and affect described in these patients and especially in the patient described by Terzian and Dalle Ore, ${ }^{30}$ are similar to, though usually less florid than, the behaviour that is observed following complete bilateral temporal lobectomies in monkeys, initially described by Klüver and Bucy. ${ }^{35-37}$ The behaviour of these animals has been described in detail. They compulsively attend to all external stimuli and constantly attempt to touch all objects within reach (hypermetamorphosis). This occurs whether or not such objects are usually regarded as dangerous (for example a snake) since the significance of both visual and auditory stimuli is lost (psychic blindness). Objects are explored sometimes by touch but there is a strong tendency to examine them by mouth (oral tendencies). Fear, anger and avoidance reactions are not displayed to the relevant stimuli (emotional blunting): the animals are "tame". Lack of discrimination during eating and sexual activity is also observed; meat, faeces and metal objects are consumed and sexual advances made towards members of the same sex or different species. This constellation of symptoms is now often referred to as the Klüver-Bucy syndrome.

The perceptual and motor deficits that result in this sort of behaviour, which may be regarded overall as a "tendency to react indiscriminately", are only partially understood. In man difficulties with visual and tactile recognition of objects at the semantic level have not been shown to be crucial. Thus patients with a classical visual object agnosia, such as that described by Taylor and Warrington, ${ }^{38}$ do not manifest Klüver-Bucy tendencies. In addition, in monkeys, inferior temporal cortex lesions may produce difficulties in visual pattern recognition without Klüver-Bucy behaviour ${ }^{39}$ and oral tendencies, hypermetamorphosis and emotional blunting may be produced by bilateral amygdala destruction whilst visual pattern recognition remains quite intact. ${ }^{40}$ The disorder can be regarded as a "limbic agnosia"40-42 linguistic and other non-limbic classification systems being intact whilst visual and tactile cues and stimuli fail to be endowed with the emotional and motivational significance necessary to normal physiological and physical interaction with the environment. Without this ability, isolation of and attention to external stimuli which should be seen as "important" does not occur and results in deterioration of behaviour into continuous, compulsive exploration (hypermetamorphosis), lack of social and emotional interaction with the environment (emotional blunting) and inappropriate satisfaction of basic drives (bizarre sexual and dietary habits). Whether sensory-limbic disconnection is important in the genesis of such behaviour as
Geschwind $^{43}$ postulated appears unproven, but the possibility remains that category-specific agnosic defects of the sort seen in JBR might contribute to the indiscriminate dietary habits. Some authors ${ }^{4445}$ have equated oral behaviour with grasping and sucking reflexes, regarding it as disinhibited primitive oral grasping and exploring behaviour and similar to that seen in infants, whilst to others ${ }^{43}$ oral behaviour represents preservation and thus discriminative use of olfactory and gustatory limbic inputs; both views may be correct and describe the result of fractionated limbic input.

Since herpes simplex encephalitis may involve temporal neocortex in addition to medial temporal lobe structures, in contrast to vascular lesions which tend to involve either medial or lateral temporal cortex but not both simultaneously, behavioural disturbances, sometimes of Klüver-Bucy type, are to be found in some survivors. However, few such cases have been reported in any detail. All have been left with severe cognitive and memory disturbances in addition to their behaviour disturbances. Most cases have come to post-mortem. Extensive temporal neocortex and rhinencephalic destruction has been found in each case.

The first case to be reported was that of Hara and Okada in $1963 .{ }^{13}$ Necropsy demonstrated the changes of acute inclusion-body encephalitis. This patient had been unable to recognise common objects or faces, compulsively touched everything and everyone, drank perfume, and ate faeces, a thermometer, hand cream, soap, an ash tray and other small objects and bit or chewed larger objects. Abnormal sexual behaviour was not prominent but the patient was very familiar with strangers, masturbated occasionally and on one occasion attempted to get into bed with a female patient. His mood was described as being euphoric or jocular. Friedman and Allen ${ }^{11}$ then described less florid behavioural disturbances in a man aged 50 years following a necrotising encephalitis probably of herpetic origin. Whilst his main deficit appears to have been amnesic he also carried out repetitious motor activities such as tapping his feet and patting his knee, made persistent sexual allusions in his conversation and was apathetic, docile and indifferent. Neither oral behaviour nor hypermetamorphosis were reported.

Following these reports Trillet $e a^{14}$ described the behaviour of a man of 23 during his partial recovery from an encephalitic illness of uncertain cause. Virology studies including titres to herpes simplex were unhelpful. Brain biopsy was not performed. EEG showed non-specific bitemporal abnormalities during the acute illness, pneumoencephalography showed focal dilatation of both temporal horns and he was left severely amnesic but 
only mildly demented. The authors thus concluded that residual focal bitemporal pathology was likely though the micro-organism remained uncertain. The patient's behaviour during the first few months after the illness is described in detail. Initially he was seen in "une phase de préhension buccale incoercible et de mastication incessante, qui va s'exercer même envers ... l'urine et les matières fécales ... papiers, de coton, fragments de drap, etc. ... Il mastique, tourne et retourne dans sa cavité buccale le contenu de celle-ci, mais ne déglutit pas ...". Indiscriminate sexual behaviour then gradually became more obvious and he would "se promene dans les couloirs, serrant dans ses bras et embrassant successivement l'interne et l'infirmière auxquels il continue d'ailleurs à proposer des 'gueuletons' dès sa sortie du Service". Later "il manifeste une nette préférence pour l'elément féminin." Following these problems "activité manuelle d'appréhension tactile répétitive, stéréotypée" became more prominent. This abnormal sexual and oral behaviour and hypermetamorphosis then regressed and one year later he was over-eating, obese, passive and severely amnesic.

Since then three other detailed case reports in English of similar behaviour disturbances following herpes simplex encephalitis have been published, two ${ }^{1218}$ with post-mortem material. Gascon and Gilles $^{12}$ emphasise the emotional blunting and amnesia producing a "limbic dementia" in a patient who also ate food, other objects and faeces indiscriminately and was restless, jocular and easily distracted. Marlowe $e t{ }^{~} l^{16}$ and Shoji $e t a l^{18}$ describe similar patients who were also inappropriately affectionate, the patient described by Shoji et $_{\text {al }}{ }^{18}$ trying "to touch the nurses on the thigh". In the Japanese literature Hiyamuta ${ }^{15}$ reported a patient with oral tendencies, hypermetamorphosis, emotional changes and hypersexuality and in 1977 Akai, Kato and Takase ${ }^{17}$ reported a well documented case and reviewed the literature. Their case exhibited oral tendencies, emotional blunting, hypermetamorphosis and visual agnosia but not aberrant sexual behaviour. Both these cases came to necropsy.

Mention should also be made of the two patients reported briefly by Oxbury and Maccallum, ${ }^{9}$ both of whom were demented and amnesic, who ate paper and their faeces, as did Shoji' ${ }^{46}$ survival case 2 , and the patient reported by Wallack ${ }^{47}$ with bulimia, childishness and amnesia following an encephalitic illness, the cause of which was unfortunately poorly documented. Pathology was not obtained in these cases.

Hierons, Janota and Corsellis ${ }^{10}$ provide the most comprehensive survey available of the spectrum of behavioural disturbances seen following a bilateral limbic encephalitis. Post-mortem material was obtained in all of the ten cases; in only two was there clear evidence that herpes simplex had been responsible although it seems the most likely cause in each case. The sequelae are described fully. Prominent oral tendencies were seen in four patients and another ate excessively. Attempts to kiss staff and other patients effusively were observed in one patient. Emotional disturbances were, however, frequently of an aggressive and destructive nature and were seen at some time in six patients. One patient became very depressed and attempted suicide repeatedly, two were withdrawn and only one was cheerful and friendly. Hypermetamorphosis was not reported.

These reports appear to indicate that oral behaviour and mood changes are the most obvious behavioural abnormalities seen after a limbic encephalitis in man. Emotional disturbances have been variable, some patients being violent and aggressive, others euphoric or inappropriately familiar and a few withdrawn or depressed. Many patients are quite unlike the "tamed" monkeys described by Klüver and Bucy. Hypermetamorphosis or other repetitive motor activity has been observed at times while obviously abnormal sexual behaviour has been relatively minor or absent. This contrasts with the patient described by Terzian and Dalle $\mathrm{Ore}^{30}$ following bitemporal lobectomy who practised "self-abuse several times a day" and showed obvious emotional blunting and hypermetamorphosis but no oral tendencies at all.

At some point during their partial recovery each of our patients demonstrated behavioural disturbances similar to those described by previous authors; oral tendencies and mood disturbances were prominent while floridly abnormal sexual behaviour was not seen. Case 1 (JBR) tended to pick up objects indiscriminately, ate everything within reach including faeces and his urinary catheter and drank large volumes of any liquid available including shampoo. Polydipsia and polyuria due to behaviour disturbance after herpes simplex encephalitis do not seem to have been reported previously. There was no other evidence to implicate hypothalamic dysfunction though this remains a possibility. Case 2 (TM) would sit chewing paper, blankets and other objects, ate his faeces and would bite at pencils, fingers and other objects placed near his face. Case 3 (KB) attempted to eat a variety of objects early on during her recovery and eighteen months after her illness would still eat any sort of food placed in front of her. Case 4 (EH) walked around the ward picking things up at random, would often put them into his mouth, ate voraciously and drank liquids indiscriminately. By contrast with these tendencies to eat, bite and chew non-food 
objects and eat bizarrely and to excess none of these patients demonstrated obviously abnormal sexual behaviour, although KB did tend to kiss or blow kisses to staff and other patients.

The emotional disturbances that were seen were varied. All four patients could be described as "emotionless in speech" 42 in that they showed a poverty of normal facial and gestural expressions of emotion during simple conversations. Further questioning and probing, however, resulted in various responses. JBR was at first watchful and suspicious and later tended to fly into rages. EH was initially aggressive and disruptive though later rather facile while KB was inappropriately affectionate and tended to be tearful with minor set-backs. TM would become aggressive and disruptive. He would shout and swear and throw food and faeces around. As a result he was extremely difficult to handle on the ward. Contrasting with this behaviour disturbance was his ability to play a simple game of chess or noughts and crosses and name current footballers or the hospital in which he was, indicating that his memory disturbance was less severe than the other three patients. Violent behaviour is well recognised in man with irritative temporal lobe pathology but is usually reversed by destructive lesions such as lobectomy ${ }^{48}$ and does not usually occur in Klüver-Bucy monkeys. The occasional occurrence in monkeys of increased aggressiveness after bilateral temporal lobectomy is usually attributed to sparing of amygdala nuclei which facilitate aggressiveness. ${ }^{49}$ There is no pathological data in our cases but it is of interest that memory was more preserved in the most violent case TM as this may suggest that some limbic structures may have been preserved. An ictal basis for these outbursts seems unlikely since fits were not seen and EEG tracings were unremarkable.

One may conclude, therefore, that the abnormal behaviour seen in monkeys following bitemporal lobectomy has seldom been exactly reproduced in man. Fragments of the Klüver-Bucy syndrome are, however, frequently described and it is useful to regard the syndrome in monkeys as a paradigm in the light of which some of the symptoms seen in man after destructive bitemporal lesion may be interpreted. Following herpes simplex encephalitis, bizarre eating, drinking, chewing and biting behaviour would seem to be most frequently reported. Hypermetamorphosis is less common but lack of emotional behaviour during simple conversation is well recognised; by contrast more exacting questioning or conversation may precipitate either inappropriately affectionate or aggressive and disruptive behaviour. The latter may result from patchy involvement of limbic structures. Bizarre sexual behaviour is unusual. Although mortality in herpes simplex encephalitis has been reduced in recent years, the incidence of neurological deficit in survivors remains high. It ,would seem likely that behaviour disturbances such as those described here will be seen more commonly following the disease than has previously been reported.

We thank Professor J Marshall and Drs AP Hopkins, C Hutchison and DM Park for permission to report these cases, and Professors L Duchen and EK Warrington, and Drs M Baba, N Murray and A Paton for help during preparation of the manuscript.

\section{References}

${ }^{1}$ Illis LS, Gostling JVT. Herpes simplex encephalitis. Bristol: Scientechnica, 1972.

${ }^{2}$ Davis JM, Davis KR, Kleinman GM, Kirchner HS, Taveras JM. Computed tomography of herpes simplex encephalitis, with clinico-pathological correlation. Radiology 1979;129:409-17.

${ }^{3}$ Dinn JJ. Distribution of herpes simplex virus in acute necrotising encephalitis. $J$ Pathol 1978;129:135-8.

4 Davis LE, Johnson RJ. An explanation for the localisation of herpes simplex encephalitis? Ann Neurol 1979;5:2-5.

${ }^{5}$ Rose FC, Symonds CP. Persistent memory defect following encephalitis. Brain 1960;83:195-212.

${ }^{6}$ Brierley JB, Corsellis JAV, Hierons R, Nevin S. Subacute encephalitis of later adult life mainly affecting the limbic areas. Brain 1960;83:357-68.

${ }^{7}$ Drachman DA, Adams RD. Herpes simplex and acute inclusion-body encephalitis. Arch Neurol 1962;7: 45-63.

${ }^{8}$ Hall P. Subacute viral encephalitis amnesia. Lancet $1965 ; \mathbf{i}: 1077$.

${ }^{9}$ Oxbury JM, Maccallum FO. Herpes simplex virus encephalitis: clinical features and residual damage. Postgrad Med J 1973;43:387-9.

${ }^{10}$ Hierons R, Janota I, Corsellis JAV. The late effects of necrotising encephalitis of the temporal lobes and limbic areas: a clinico-pathological study of 10 cases. Psychol Med 1978;8:21-42.

"Friedman HM, Allen N. Chronic effects of complete limbic lobe destruction in man. Neurology (Minneap) 1969;19:679-90.

${ }^{12}$ Gascon GG, Gilles F. Limbic dementia. J Neurol Neurosurg Psychiatry 1973;36:421-30.

${ }^{13}$ Hara T, Okada M. A case of acute necrotising encephalitis. Lesions in the limbic areas and KlüverBucy's syndrome. Psychiatr Neurol Jap 1963;65: 715-25.

${ }^{14}$ Trillet M, Schott B, Michel D, Barbizet J, Duizabo P. Syndrome de type Klüver et Bucy et amnésie de fixation consécutifs à une encephalite aigüe. J Med Lyon 1969;225:939-56.

${ }^{15}$ Hiyamuta E. Klüver-Bucy syndrome. Geriatric Med (Tokyo) 1974;12:713-7.

${ }^{16}$ Marlowe WB, Mancall EL, Thomas JJ. Complete Klüver-Bucy syndrome in man. Cortex 1975;11:53-9.

${ }^{17}$ Akai J, Kato Y, Takase M. Etude clinico-pathologique concernant syndrome de Klüver-Bucy chez l'homme. 
Psychiatr Neurol Jap 1977;79:67-87.

${ }^{18}$ Shoji H, Teramoto H, Satowa S, Satowa H, Narita Y. Partial Klüver-Bucy syndrome following probable herpes simplex encephalitis. J Neurol 1979;221:1637.

${ }^{19}$ Whitley RJ, Soong S-J, Hirsch MS, et al. Herpes simplex encephalitis: vidarabine therapy and diagnostic problems. New Eng J Med 1981;304:313-8.

${ }^{20}$ Warrington EK. Neuropsychological studies of verbal semantic systems. Phil Trans $R$ Soc Lond $B$ 1981;295:411-23.

${ }^{21}$ Scoville WB, Milner B. Loss of recent memory after bilateral hippocampal lesions. J Neurol Neurosurg Psychiatry 1957;20:11-21.

${ }^{22}$ Glees P, Griffith HB. Bilateral destruction of the hippocampus (cornu ammonis), in a case of dementia. Monatsschr Psychiatr Neurol 1952;123:192-204.

${ }^{23}$ Victor M, Angerine JB, Mancall EL, Fisher CM. Memory loss with lesions of hippocampal formation. Arch Neurol 1961;5:244-63.

${ }^{24}$ De Jong RN; Itabashi HH, Olson JR. Memory loss due to hippocampal lesions. Arch Neurol 1969;20:339 48.

${ }^{25}$ Brindley GS, Janota IG. Observations on cortical blindness and on vascular lesions that cause memory loss. $J$ Neurol Neurosurg Psychiatry 1975;138:459-64.

${ }^{26}$ Lishman WA. Organic Psychiatry. Oxford: Blackwell, 1978.

${ }^{27}$ Green JR, Duisberg REH, Mcgrath WB. Focal epilepsy of psychomotor type. A preliminary report of observations on effects of surgical therapy. $J$ Neurosurg $1951 ; 8: 157-72$.

${ }^{28}$ Pool JL. The visceral brain of man. J Neurosurg 1954;11:45-63.

${ }^{29}$ Hill D, Pond DA, Mitchell W, Falconer MA. Personality changes following temporal lobotomy for epilepsy. $J$ Men Sci 1957;103:18-27.

${ }^{30}$ Terzian H, Dalle Ore G. Syndrome of Klüver and Bucy. Reproduced in man by bilateral removal of the temporal lobes. Neurology (Minneap) 1955;5:372-80.

${ }^{31}$ Balajthy B. Symptomatology of the temporal lobe in Pick's convulutional atrophy. Acta Med Acad Sci Hung 1964;20:304-16.

${ }^{32}$ Pilleri G. The Klüver-Bucy syndrome in man. A clinico-anatomical contribution to the function of the medial temporal lobe structures. Psychiatr Neurol (Basel) 1966;152:65-103.

${ }^{33}$ Aronson SM, Aronson BE. Clinical neuropathological conference. Dis Nerve Sys 1973;34:124-30.

${ }^{34}$ Cummings JL, Duchen LW. Klüver-Bucy syndrome in
Pick's disease: clinical and pathologic correlations. Neurol (NY) 1981;31:1415-22.

${ }^{35}$ Klüver H, Bucy PC. Psychic blindness and other symptoms following bilateral temporal lobectomy in Rhesus monkeys. Am J Physiol 1937;119:352-3.

${ }^{36}$ Klüver H, Bucy PC. An analysis of certain effects of bilateral temporal lobectomy in the Rhesus monkey, with specific references to psychic blindness. J Psychol 1938;5:33-54.

${ }^{37}$ Klüver H, Bucy PC. Preliminary analysis of functions of the temporal lobes in monkeys. Arch Neurol Psychiatr 1939;42:979-1000.

${ }^{38}$ Taylor A, Warrington EK. Visual agnosia: a single case report. Cortex 1971;7:152-61.

${ }^{39}$ Bagshaw MH, Mackworth NH, Pribram KH. The effect of resections of the inferotemporal cortex of the amygdala on visual orienting and habituation. Neuropsychologia 1972;10:153-62.

${ }^{40}$ Horel JA, Keating EG, Misantone LJ. Partial KlüverBucy syndrome produced by destroying temporal neocortex or amygdala. Brain Res 1975;94:347-59.

${ }^{41}$ Gloor P. Inputs and outputs of the amygdala: what the amygdala is trying to tell the rest of the brain. In: Livingstone $\mathrm{KC}$, Hornykiewicz $\mathrm{O}$, eds. Limbic Mechanisms: the Continuing Evolution of the Limbic System Concept. New York: Plenum, 1978:189-209.

${ }^{42}$ Bear DM. Temporal lobe epilepsy-a syndrome of sensory-limbic hyperconnection. Cortex 1979;15: 357-84.

${ }^{43}$ Geschwind N. Disconnexion syndromes in animals and man. Brain 1965;88:237-54.

${ }^{44}$ Pilleri G. The Klüver-Bucy syndrome in man. Psychiat Neurol (Basel) 1966;152:65-103.

${ }^{45}$ Poeck K. Pathophysiology of emotional disorders associated with brain damage. In: Vinken PJ, Bruyn GW, eds. Handbook of Clinical Neurology, Vol 3. Amsterdam: North Holland Publ Co, 1968:343-67.

${ }^{46}$ Shoji H. Clinical features of herpes simplex encephalitis. Clin Neurol (Tokyo) 1973;8:491-8.

${ }^{47}$ Wallack E. Selective limbic deficits after encephalitis. South Med J 1976;65:669-71.

${ }^{48}$ Moyer KE. The physiology of aggression and the implications for aggression control. In: Moyer $\mathrm{KE}$, ed. Physiology of Aggression and Implications for Aggression Control: an Anthology of Readings. New York: Raven Press, 1976:233-60.

${ }^{49}$ Siegel A, Flynn JP. Differential effects of electrical stimulation and lesions of the hippocampus and adjacent regions upon attack behaviour in cats. Brain Res 1968;7:252-67. 